Transition from the Taylor rule to the zero lower bound

Stan Hurn, Nicholas Johnson, Annastiina Silvennoinen and Timo Teräsvirta

CREATES Research Paper 2018-31 


\title{
Transition from the Taylor rule to the zero lower bound
}

\author{
Stan Hurn, Nicholas Johnson $\ddagger$ Annastiina Silvennoinen ${ }^{\ddagger}$ \\ School of Economics and Finance, Queensland University of Technology

\section{Timo Teräsvirta ${ }^{\S}$} \\ CREATES, Department of Economics and Business, Aarhus University, Denmark \\ C.A.S.E., Humboldt-Universität zu Berlin \\ and \\ School of Economics and Finance, Queensland University of Technology
}

November 2018

\begin{abstract}
This paper examines the Taylor rule in the context of United States monetary policy since 1965, particularly with respect to the zero-lower-bound era of the federal funds rate from 2009 to 2016. A nonlinear Taylor rule is developed which features smooth transitions in the first two moments of the federal funds rate. This flexible specification is found to usefully capture observed nonlinearity, while accounting for the well-documented structural changes in monetary policy formation at the Federal Reserve in the last fifty years, and especially in the recent zero-lower-bound era.

*e-mail: s.hurn@qut.edu.au

$\dagger$ †-mail: njohnson@ecwb.org (Corresponding Author)

$\ddagger$ e-mail: silvennoinen@qut.edu.au

§e-mail: tterasvirta@econ.au.dk
\end{abstract}


Keywords: liquidity trap, regime switching, smooth transition, structural change, unconventional monetary policy

JEL Classification: C22, C51, C54

Acknowledgments This research has been supported by the Center for Research in Econometric Analysis of Time Series (CREATES), funded by the Danish National Research Foundation, Grant No. DNRF 78. Funding from the National Centre for Econometric Research, Queensland University of Technology, Brisbane, is also gratefully acknowledged. Material from the paper has been presented at the 26th Annual Symposium of the Society for Nonlinear Dynamics and Econometrics, Keio University, Tokyo, March 2018, Computing in Economics and Finance (CEF 2018), Università Cattolica del Sacro Cuore, Milan, June 2018, and a seminar at Aarhus University. Comments from participants are gratefully acknowledged. Any errors and shortcomings in this work are the authors' own responsibility. 


\section{Introduction}

The beauty of the Taylor rule and the primary reason for its longevity is its simplicity; the central bank is seen to use a straightforward interest-rate rule when conducting monetary policy. Indeed, the popularity of the rule has survived its well-documented instability. It is an undeniable fact, however, that after the financial crisis of 2007-2009 the United States economy experienced a sharp contraction in economic activity and a prolonged slow recovery. At the same time, the federal funds rate fell and remained at its effective lower bound of zero for a protracted period of time. This period of policy at the zero lower bound calls into question the applicability of a simple linear reaction function linking inflation and economic activity to the short-term interest rate. Consequently, this paper develops and estimates a nonlinear Taylor rule that maintains the simplicity and tractability of the original and also accommodates the nonlinearity induced by the zero-lower bound.

The original Taylor rule (Taylor 1993) represented the target short-term interest rate as a linear function of inflation and output gap. The Taylor rule aligns nicely with the dual mandate of the Federal Reserve (introduced in 1977) which requires that the Board of Governors and the FOMC must act to dampen the business cycle and provide a measure of stability to the economy by promoting "maximum employment, stable prices, and moderate long-term interest rates." The last point can be achieved by inducing inflation to fall, which is one of the two key explanatory variables in the Taylor rule. The second key explanatory variable (output gap) relates to employment via Okun's (1962) law.

Several variations to the simple linear Taylor rule have been proposed during the last twenty years. Gonzales and Vera (2002), Nikolsko-Rzhevskyy, Papell and Prodan (2014), and Creel and Hubert (2015) replace the output gap variable with the negative unemployment gap. Other papers vary the linear Taylor rule by way of the assumed time horizon used by the monetary authority; they may use current data, lagged (backward-looking) data, or expected (forward-looking) data. Others have experimented with including explanatory variables in addition to the contemporaneous values of the inflation and output gap. For instance, Clarida, Galí and Gertler (1998), Taylor (1999b, 2001), Casellina and Uberti (2008), Aizenman, Hutchison and Noy (2011), and Caporale, Helmi, Çatık, Ali and Akdeniz (2018) all use the real exchange rate in the estimation of their Taylor rule models. By contrast, the Taylor rule papers by Fuhrer and Tootell (2008), Bauducco, 
Bulír and Čihák (2008), Alcidi, Flamini and Fracasso (2011), Kasaï and Naraidoo (2012), Lee and Son (2013), and Roskelley (2016) all feature some variable representing activity in the financial markets.

A wealth of literature on the Taylor rule has found that the historically unusual high values of the federal funds rate between 1978 and 1983, coinciding with the Federal Reserve Chair transitions from Burns to Miller and from Miller to Volcker, pose serious parameter instability problems for the estimation of the linear Taylor rule in this era. A variety of nonlinear Taylor rule model specifications, which include smooth transitions, thresholds, Markov-switching and time-varying parameters, have been previously proposed to accommodate the apparent structural instabilities (Kim, Osborn and Sensier 2005, Boivin 2006, Petersen 2007, Koustas and Lamarche 2012).

As already mentioned, the approach taken in this paper is to propose a nonlinear model for the interest rate that explicitly accounts for the era spent in the proximity of the zero lower bound after 2008, where the Taylor rule relationship 'breaks down' (Martin and Milas 2013, Bhar and Malliaris 2016). The majority of the Taylor rule literature avoids this problematic era entirely by restricting estimation to time periods ending in or before 2007. In this paper, the smooth transition regression zero-lower-bound (STR-ZLB) model for the Taylor rule is introduced. Specifically, this smooth transition specification also extends to the conditional variance in the federal funds rate, permitting the error variance to adjust in line with the persistence observed during the period in which the federal funds rate was at the zero lower bound, see Figure 1. This feature not only adjusts the the Taylor rule in the presence of the zero lower bound but it also permits modelling of recovery from the lower bound, a feature that is consistent with recent observed behaviour.

\section{Models for the Taylor rule}

The traditional rule for target short-term interest rate in the United States introduced by Taylor (1993) is given by

$$
i_{t}=\alpha_{0}+\alpha_{1} \pi_{t}+\alpha_{2} y_{t}
$$

in which $y_{t}$ is the output gap, measured as the difference between the real GDP and the estimated potential real GDP, and $\pi_{t}$ is year-on-year percentage change in aggregate 


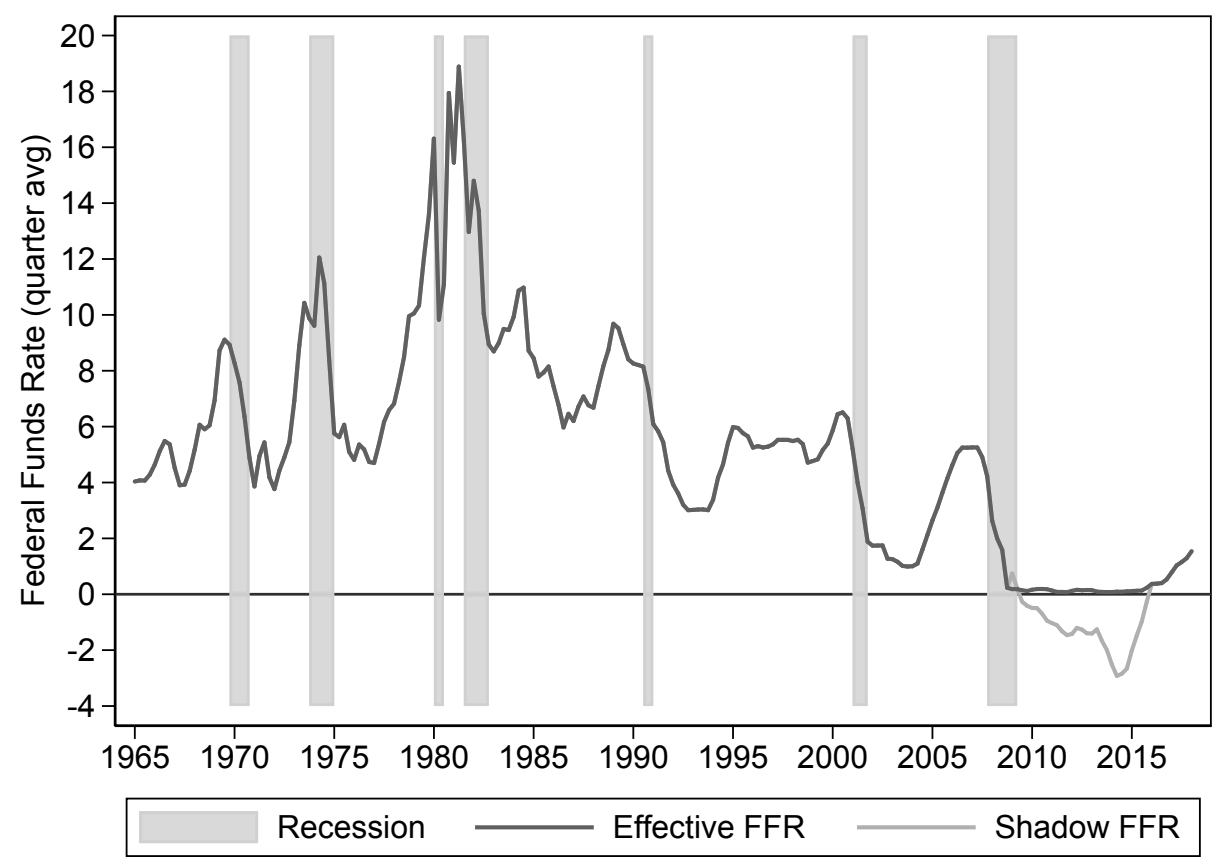

Figure 1: The quarterly-averaged United States federal funds rate from 1965:Q1 to 2018:Q1. The shadow rate plotted when the effective federal funds rate is at the zero lower bound is that of $\mathrm{Wu}$ and Xia (2015).

prices (actual inflation). For the years from 1987 to 1992, Taylor proposed that the output and inflation gaps entered this reaction function with equal weights of 0.5 , and that the equilibrium real interest rate and the inflation target were identically equal to $2 \%$, yielding parameter values $\alpha_{0}=1, \alpha_{1}=1.5$, and $\alpha_{2}=0.5$.

The Taylor rule can be interpreted to mean that the Federal Reserve raises the federal funds rate target for the short-term nominal interest rate when inflation rises above its desired level and/or the output level rises above trend. Of course, the target output deviation from its natural rate is zero because output cannot exceed potential output in the long run. The Taylor rule assumes a small positive inflation rate because deflation is considered a worse outcome for the economy than controlled inflation. For discussion, see Nikolsko-Rzhevskyy and Papell (2013).

A static Taylor rule model would have a poor fit to the data because of the welldocumented persistence in short-term interest rates. Accordingly, it is usual to assume that central banks do not adjust interest rates abruptly but rather smooth them. See Goodfriend (1991), and Rudebusch $(2002,2006)$ for an extended discussion of monetary 
policy inertia and interest rate smoothing. Clarida et al. (1998) suggested an interest rate smoothing whereby the standard rule is augmented by a lag of the interest rate,

$$
i_{t}=\left(1-\alpha_{3}\right)\left(\bar{\alpha}_{0}+\bar{\alpha}_{1} \pi_{t}+\bar{\alpha}_{2} y_{t}\right)+\alpha_{3} i_{t-1}=\alpha_{0}+\alpha_{1} \pi_{t}+\alpha_{2} y_{t}+\alpha_{3} i_{t-1},
$$

where $\bar{\alpha}_{0}, \bar{\alpha}_{1}$, and $\bar{\alpha}_{2}$ are the long-run coefficient values. Fuhrer (1997) suggested an even more dynamic decision rule with lags on inflation and output gap as well.

Even the augmented version of the Taylor rule, however, cannot be wholly operative in the case where the interest rate approaches the zero lower bound.

Reifschneider and Williams (2000) were among the first to point out that the original Taylor rule is inferior to nonlinear specifications when it comes to stabilization capability in the presence of the zero lower bound. In the vicinity of the zero lower bound, the original formulation of the Taylor rule is no longer applicable due to its failure to account for the implied positive constraint on the interest rate. Liquidity traps were largely considered to be a theoretical textbook phenomenon until February 12, 1999, when the Bank of Japan announced the lowering of overnight interest rates to be 'as low as possible' in an attempt to avoid a downward deflationary spiral, see Jung, Teranishi and Watanabe (2005). This situation brought about heightened research interest in monetary policy at the zero lower bound. $^{1}$

As an example, consider the following nonlinear specification of the interest rate due to Ruge-Murcia (2006). Let the nominal interest rate, $i_{t}$, take the form of a limited dependent variable generated by an underlying unobserved latent index, $i_{t}^{*}$, as follows:

$$
i_{t}= \begin{cases}i_{t}^{*} & \text { if } i_{t}^{*}>0 \\ 0, & \text { otherwise }\end{cases}
$$

The unobserved latent index, $i_{t}^{*}$, is called the shadow rate. Now let the dynamics of $i_{t}^{*}$ be generated by

$$
i_{t}^{*}=\alpha+\sum_{j=1}^{p} \phi_{j} i_{t-j}+\beta^{\prime} \mathbf{x}_{t}+\varepsilon_{t},
$$

where $\alpha \geq 0$, and $\mathbf{x}_{t}$ is a vector of explanatory variables. Combining (2) and (3) means that $i_{t}^{*}$ is censored and that the behaviour of $i_{t}$ is described by a Tobit model

\footnotetext{
${ }^{1}$ The European Central Bank introduced negative interest rates in 2014, and the Japanese call rate was set negative for the first time in early 2016.
} 
Amemiya (1984). The error $\varepsilon_{t}$ has mean zero and the conditional error variance follows a $\operatorname{GARCH}(1,1)$ model. Consequently, $\mathrm{E} \varepsilon_{t} \varepsilon_{t-j}=0$ for $j \neq 0$. Although Ruge-Murcia (2006) uses this model for bond pricing, it can easily be employed as a nonlinear Taylor rule.

Taylor and Williams (2011) suggested a specification to accommodate the zero lower bound within the framework in the Taylor rule, given by,

$$
i_{t}=\max \left\{0, E\left[\left(1-\alpha_{3}\right)\left(\bar{\alpha}_{0}+\bar{\alpha}_{1} \pi_{t}+\bar{\alpha}_{2} y_{t}\right)+\alpha_{3} i_{t-1}^{*}\right]\right\}
$$

where $i_{t-1}^{*}$ denotes the lagged level of the interest rate that would occur in the absence of the zero lower bound. It is in fact the unconstrained shadow rate and replaces the actual rate in $(1)$.

Left-censoring of monetary policy reaction functions has been previously estimated using a Tobit approach by authors such as Kato and Nishiyama (2005) and Huang (2015). Equation (4) is not an econometric model, but its structure is similar to the model of RugeMurcia (2006), in which the observable interest rate is prevented from becoming negative, so that the zero-lower-bound constraint is binding.

While these nonlinear specifications based on censoring provide easy-to-estimate alternatives to the simple linear Taylor rule, they are not developed any further here. Rather, our approach is to develop a dynamic model of the interest rate at the zero lower bound that describes the nonlinearity imposed by this constraint but also recognises that the behaviour of the error variance must be adapted to account for the existence of the bound.

\section{A zero-lower-bound smooth transition model}

The model proposed here is based on the same idea as the smooth transition autoregressive target zone (STARTZ) model due to Lundbergh and Teräsvirta (2006). The STARTZ model characterises the behaviour of an exchange rate that is restricted to fluctuate within a band and is a discrete-time version of the continuous time model of Krugman (1991). The dynamic behaviour of the exchange rate is very different when it approaches a boundary it cannot breach from what it is further away from these bounds. The present situation is somewhat simpler than that of the target zone as the interest rate only has a 
(zero) lower bound. The conditional mean component of the model embeds both a Taylor rule regime and a zero-lower-bound regime and is defined as follows:

$$
\begin{aligned}
i_{t} & =\left(\alpha_{0}+\alpha_{1} \pi_{t}+\alpha_{2} y_{t}+\alpha_{3} i_{t-1}\right) G_{m}\left(i_{t-1}\right)+\left(\alpha_{4}+\alpha_{5} i_{t-1}\right)\left(1-G_{m}\left(i_{t-1}\right)\right)+\varepsilon_{t} \\
& =\left(\alpha_{0}^{*}+\alpha_{1} \pi_{t}+\alpha_{2} y_{t}+\alpha_{3}^{*} i_{t-1}\right) G_{m}\left(i_{t-1}\right)+\alpha_{4}+\alpha_{5} i_{t-1}+\varepsilon_{t} \\
& =i_{t}^{\circ} G_{m}\left(i_{t-1}\right)+\alpha_{4}+\alpha_{5} i_{t-1}+\varepsilon_{t},
\end{aligned}
$$

where $\varepsilon_{t}$ is white noise, $\mathrm{E} \varepsilon_{t}=0$ and $\mathrm{E} \varepsilon_{t}^{2}=\sigma^{2}$. The conditional variance of $\varepsilon_{t}$ will be considered later. In the lower bound regime, the linear Taylor rule breaks down and inflation and the output no longer predict the interest rate, hence their absence from that regime. The parameters $\alpha_{0}^{*}=\alpha_{0}-\alpha_{4}$ and $\alpha_{3}^{*}=\alpha_{3}-\alpha_{5}$ have been constructed for the ease of estimation. If needed, the original parameters $\alpha_{0}$ and $\alpha_{3}$ can be recovered from these relations.

The transition function $G_{m}(\cdot)$ of the STARTZ model is a generalized logistic function because the smooth pasting assumption is essential to the modelling of an exchange rate in the target zone. Since this assumption is not needed here and transition variable $i_{t} \geq 0$ almost surely, we follow Lanne and Saikkonen (2005) who suggested the use of the function $G\left(i_{t-1}\right):(0, \infty) \rightarrow[0,1]$. Their suggestion of using the cumulative distribution function of the single parameter gamma distribution as the transition function is adopted here. Consequently the transition function in (5) is given by

$$
G_{m}\left(i_{t-1}\right)=G_{m}\left(i_{t-1} ; \gamma_{m}\right)=\frac{1}{\Gamma\left(\gamma_{m}\right)} \int_{0}^{i_{t-1}} e^{-s} s^{\gamma_{m}-1} \mathrm{~d} s
$$

where $\gamma_{m}$ is the shape parameter and the implied scale parameter has been set equal to one.

This form of the transition function (6) is properly known as a regularized lower incomplete gamma function, and is a bounded, monotonically increasing function of $i_{t-1}$. It does not have a closed-form representation, so its values have to be computed numerically. ${ }^{2}$ When $G_{m}\left(i_{t-1}\right)=1$, the behaviour of the interest rate is determined by the linear dynamic Taylor rule, whereas when $G_{m}\left(i_{t-1}\right) \rightarrow 0$, which happens when the interest rate approaches zero, the Taylor rule is no longer operational. More generally, the interest rate for a given

\footnotetext{
${ }^{2}$ In the application the two-parameter gamma c.d.f. was also tried, but using it barely increased the maximum value of the likelihood and substantially slowed down convergence.
} 
$i_{t-1} \geq 0$ is a convex combination of the Taylor rule equation and a simple $\mathrm{AR}(1)$ model for $i_{t-1}$.

In order to model an implied persistent regime for the interest rate at the zero lower bound, the variance of $\varepsilon_{t}$ also has to be time-varying and appropriately parameterized. The conditional variance is decomposed as in the well known ARCH model Engle (1982). Thus $\varepsilon_{t}=z_{t} h_{t}^{1 / 2}$, where $z_{t} \sim \operatorname{iid} \mathcal{N}(0,1)$. The conditional variance $h_{t}$ is a function of $i_{t-1}$ given by

$$
h_{t}=\delta+(d-\delta) G_{v}\left(i_{t-1}\right),
$$

where

$$
G_{v}\left(i_{t-1}\right)=G_{v}\left(i_{t-1} ; \gamma_{v}\right)=\frac{1}{\Gamma\left(\gamma_{v}\right)} \int_{0}^{i_{t-1}} e^{-s} s^{\gamma_{v}-1} \mathrm{~d} s
$$

Both $d$ and $\delta$ are positive parameters, with $\delta$ very close to zero, and, consequently, $d-\delta>0$. When the interest rate is close to zero, $G_{v}\left(i_{t-1}\right)$ is also expected to either equal zero or be very close to zero, in which case the error variance is small. In this sense, the zero-lower-bound constraint is not strictly binding, but by design is unlikely to be crossed without the action of a sufficient exogenous shock. ${ }^{3}$ The error variance increases with $i_{t-1}$ and approaches $d$ when the interest rate is sufficiently large. The model defined by (5), (6), (7) and (8) may be called the smooth transition regression zero-lower-bound (STR-ZLB) Taylor rule model.

\section{Log-likelihood, score and the information matrix}

The log-likelihood function of the STR-ZLB model for observation $t$ has the form

$$
\ell_{t}=k-\frac{1}{2} \ln h_{t}-\frac{\varepsilon_{t}^{2}}{2 h_{t}}
$$

where

$$
\varepsilon_{t}=i_{t}-i_{t}^{\circ} G_{m}\left(i_{t-1}\right)-\alpha_{4}-\alpha_{5} i_{t-1}
$$

for $t=1, \ldots, T$. Let the mean parameter vector be $\theta_{m}=\left(\alpha_{0}^{*}, \alpha_{1}, \alpha_{2}, \alpha_{3}^{*}, \alpha_{4}, \alpha_{5}, \gamma_{m}\right)^{\prime}$ and the variance parameter vector be $\theta_{v}=\left(\delta, d, \gamma_{v}\right)^{\prime}$ and further set $\theta=\left(\theta_{m}^{\prime}, \theta_{v}^{\prime}\right)^{\prime}$. Then the

\footnotetext{
${ }^{3}$ The model does permit very small negative interest rates to occur and so could feasibly be used outside of the United States context.
} 
score for observation $t$ equals

$$
\frac{\partial \ell_{t}}{\partial \theta}=\left(\frac{\partial \ell_{t}}{\partial \theta_{m}^{\prime}}, \frac{\partial \ell_{t}}{\partial \theta_{v}^{\prime}}\right)^{\prime}
$$

In (10), the partial derivatives w.r.t. the mean parameters are

$$
\begin{aligned}
\frac{\partial \ell_{t}}{\partial \theta_{m}} & =\frac{\varepsilon_{t}}{h_{t}}\left(G_{m}\left(i_{t-1}\right), \pi_{t} G_{m}\left(i_{t-1}\right), y_{t} G_{m}\left(i_{t-1}\right), i_{t-1} G_{m}\left(i_{t-1}\right), 1, i_{t-1}, i_{t}^{\circ} \frac{\partial G_{m}\left(i_{t-1}\right)}{\partial \gamma_{m}}\right)^{\prime} \\
& =\frac{\varepsilon_{t} \mathbf{s}_{m t}}{h_{t}}
\end{aligned}
$$

with

$$
\begin{aligned}
\frac{\partial G_{m}\left(i_{t-1}\right)}{\partial \gamma_{m}} & =-\psi\left(\gamma_{m}\right) G_{m}\left(i_{t-1}\right)+\frac{1}{\Gamma\left(\gamma_{m}\right)} \int_{0}^{i_{t-1}} e^{-s} s^{\gamma_{m}-1}(\ln s) \mathrm{d} s \\
& =\frac{1}{\Gamma\left(\gamma_{m}\right)} \int_{0}^{i_{t-1}} e^{-s} s^{\gamma_{m}-1}\left(\ln s-\psi\left(\gamma_{m}\right)\right) \mathrm{d} s
\end{aligned}
$$

where $\psi\left(\gamma_{m}\right)$ is the digamma function. The partial derivatives w.r.t. the variance parameters are

$$
\begin{aligned}
\frac{\partial \ell_{t}}{\partial \theta_{v}} & =\frac{1}{2 h_{t}}\left(\frac{\varepsilon_{t}^{2}}{h_{t}}-1\right)\left(1-G_{v}\left(i_{t-1}\right), G_{v}\left(i_{t-1}\right),(d-\delta) \frac{\partial G_{v}\left(i_{t-1}\right)}{\partial \gamma_{v}}\right)^{\prime} \\
& =\frac{1}{2 h_{t}}\left(\frac{\varepsilon_{t}^{2}}{h_{t}}-1\right) \mathbf{s}_{v t},
\end{aligned}
$$

where, analogous to (11),

$$
\frac{\partial G_{v}\left(i_{t-1}\right)}{\partial \gamma_{v}}=-\psi\left(\gamma_{v}\right) G_{v}\left(i_{t-1}\right)+\frac{1}{\Gamma\left(\gamma_{v}\right)} \int_{0}^{i_{t-1}} e^{-s} s^{\gamma_{v}-1}(\ln s) \mathrm{d} s
$$

The information matrix for observation $t$ is given by

$$
\mathbf{I}\left(\theta^{0}\right)=\left[\begin{array}{cc}
\left.\mathrm{E} \frac{\partial \ell_{t}}{\partial \theta_{m}} \frac{\partial \ell_{t}}{\partial \theta_{m}^{\prime}}\right|_{\theta_{m}=\theta_{m}^{0}} & \mathbf{0} \\
\mathbf{0}^{\prime} & \left.\mathrm{E} \frac{\partial \ell_{t}}{\partial \theta_{v}} \frac{\partial \ell_{t}}{\partial \theta_{v}^{\prime}}\right|_{\theta_{v}=\theta_{v}^{0}}
\end{array}\right]
$$

where $\theta_{m}^{0}$ and $\theta_{v}^{0}$ are true parameter vectors,

$$
\left.\mathrm{E} \frac{\partial \ell_{t}}{\partial \theta_{m}} \frac{\partial \ell_{t}}{\partial \theta_{m}^{\prime}}\right|_{\theta_{m}=\theta_{m}^{0}}=\mathrm{E} \frac{1}{h_{t}^{0}} \mathbf{s}_{m t}^{0}\left(\mathbf{s}_{m t}^{0}\right)^{\prime}
$$

and

$$
\left.\mathrm{E} \frac{\partial \ell_{t}}{\partial \theta_{v}} \frac{\partial \ell_{t}}{\partial \theta_{v}^{\prime}}\right|_{\theta_{v}=\theta_{v}^{0}}=\frac{1}{2} \mathrm{E} \frac{1}{h_{t}^{0}} \mathbf{s}_{v t}^{0}\left(\mathbf{s}_{v t}^{0}\right)^{\prime}
$$

where $\mathbf{s}_{m t}^{0}$ and $\mathbf{s}_{v t}^{0}$ are the true values (true parameter values under $\mathrm{H}_{0}$ ) of $\mathbf{s}_{m t}$ and $\mathbf{s}_{v t}$, respectively, and $h_{t}^{0}$ is the true value of the conditional variance $h_{t}$. There are no closed form expressions for the expectations (14) and (15). 


\section{Estimation of the STR-ZLB Taylor rule}

The data used here comprise quarterly United States time series for the period 1965:Q1 to 2018:Q1 for a total of 213 observations. The dependent variable is the quarterly averaged effective federal funds rate, derived from the monthly time series found in the FRED databases and expressed in basis points. For the contemporaneous output gap measure, real-time real GDP data obtained from the Philadelphia Federal Reserve are used and the gap is constructed as the difference between GDP and potential GDP, where the latter is constructed using a quadratic filter of actual GDP. ${ }^{4}$ Finally, inflation is calculated as the percentage annual change in the real-time GDP deflator, also obtained from the Philadelphia Federal Reserve.

Before estimating the STR-ZLB Taylor rule over the full timespan of the dataset, it is interesting to see the characteristics of the dynamic linear Taylor rule before the federal funds rate was reduced towards the zero lower bound in 2008. The estimation results over the 170 observations from 1965:Q1-2007:Q3 are

$$
i_{t}=\underset{(0.234)}{0.094}+\underset{(0.053)}{0.131} \pi_{t}+\underset{(0.029)}{0.055} y_{t}+\underset{(0.039)}{0.900 i_{t-1}}+\hat{\varepsilon}_{t}
$$

with standard errors in parentheses. Before the onset of the zero lower bound, it is clear that the response coefficients to inflation and the output gap are both positive and reasonably significant. All the magnitudes of the parameters are in line with those reported in previous studies, see for example Rudebusch (2006) and Martin and Milas (2010).

It is equally instructive to confirm that the dynamic linear Taylor rule breaks down after the onset of the zero lower bound. The estimation results over the 33 observations

\footnotetext{
${ }^{4} \mathrm{~A}$ number of different filters have been used to generate potential output. These include a linear and quadratic filters and the Hodrick-Prescott (HP) filter. The linear filter produces an output gap that is almost exclusively positive and is thus discarded. The real-time quadratic and HP output gaps, however, are much more commonly used in the literature Boinet and Martin (2008). As pointed out in NikolskoRzhevskyy et al. (2014), however, the HP output gap tends to empirically understate the output gap during periods of peak unemployment in the 1970s and 1980s. More generally, Hamilton (2017) argues convincingly that one should not apply the HP filter. As a consequence, the quadratic output gap is used in this work.
} 
from 2007:Q4-2015:Q4 are

$$
i_{t}=\underset{(0.197)}{0.039}+\underset{(0.084)}{0.002 \pi_{t}}+\underset{(0.055)}{0.010} y_{t}+\underset{(0.114)}{0.712 i_{t-1}}+\hat{\varepsilon}_{t},
$$

where, as before, standard errors are in parentheses.

The difference is stark. Here the short run response to inflation and the output is almost zero, and the equation is practically autoregressive of order one. A pure AR(1) model fitted to this period has the following form:

$$
i_{t}=\underset{(0.436)}{0.013}+\underset{(0.034)}{0.732 i_{t-1}}+\hat{\varepsilon}_{t} .
$$

These results are consistent with the conclusions drawn in other studies such as Jung et al. (2005) and Zhu and Chen (2017).

The STR-ZLB model (5), (6), (7) and (8) contains the pre-zero-lower-bound dynamic Taylor rule and the zero-lower-bound regime as extreme cases. Its parameters are estimated by maximum likelihood. Estimation is started from several initial values to increase the probability that the highest local maximum found is a global maximum. The scale parameters $\gamma_{m}$ and $\gamma_{v}$ in (6) and (8) are replaced by $\eta_{m}=\ln \gamma_{m}$ and $\eta_{v}=\ln \gamma_{v}$, respectively. This transformation has the advantage that the estimation becomes computationally easier when the scale parameters $\gamma_{m}$ and $\gamma_{v}$ are small (the value of the function increases rapidly with its argument). In addition, the estimate of the very small positive parameter $\delta$ in (7) is kept positive by setting $\delta=k^{2}$.

The estimated conditional mean of the STR-ZLB model is given by (with standard error estimates in parentheses)

$\left.i_{t}=\underset{(0.299)}{0.013}+\underset{(0.036)}{0.102 \pi_{t}}+\underset{(0.020)}{0.037} y_{t}+\underset{(0.052)}{\left.0.936 i_{t-1}\right)} \widehat{G}_{m}\left(i_{t-1}\right)+\underset{(0.090)}{(0.051}+\underset{(0.330)}{0.815 i_{t-1}}\right)\left(1-\widehat{G}_{m}\left(i_{t-1}\right)\right)+\widehat{\varepsilon}_{t}$,

where

$$
\widehat{G}_{m}\left(i_{t-1}\right)=\frac{1}{\Gamma(1.809)} \int_{(1.487)}^{i_{t-1}} e^{-s} s^{0.809}(1.487) \mathrm{d} s .
$$

The estimated conditional variance is

$$
\widehat{h}_{t}=\underset{(0.045)}{0.150}+\underset{(3.525)}{(7.302}-\underset{(0.045)}{0.150)} \widehat{G}_{v}\left(i_{t-1}\right)
$$

with

$$
\widehat{G}_{v}\left(i_{t-1}\right)=\frac{1}{\Gamma(11.244)} \int_{0}^{i_{t-1}} e^{-s} s^{10.481)}{ }^{(1.441)} \mathrm{d} s .
$$


Plots of the residuals $\hat{\varepsilon}_{t}$ and the standardised residuals $\hat{z}_{t}$ can be found in Figures $2 \mathrm{a}$ and $2 \mathrm{~b}$, respectively. The effect of the STR-ZLB model having captured most of the timevariation in the error variance is apparent. It appears though that the residuals contain autocorrelation, which counters the assumption that the standardised errors $\varepsilon_{t} / h_{t}^{1 / 2}$ of the model are not serially correlated. To test this assumption, the Godfrey-Breusch test of no error autocorrelation was applied. The test is based on

$$
z_{t}=\phi_{1} z_{t-1}+\ldots+\phi_{p} z_{t-p}+\zeta_{t}=\phi^{\prime} \mathbf{z}_{t-1}+\zeta_{t}
$$

where $\mathbf{z}_{t}=\left(z_{t}, z_{t-1}, \ldots, z_{t-p+1}\right)^{\prime}, \phi=\left(\phi_{1}, \ldots, \phi_{p}\right)^{\prime}$, and $\zeta_{t} \sim \operatorname{iid} \mathcal{N}\left(0, \sigma_{\zeta}^{2}\right)$. The null hypothesis is $\mathrm{H}_{0}: \phi=\mathbf{0}$. The robust version of the test is carried out in the $T R^{2}$ form by the following steps, see Godfrey (1978) and Wooldridge (1990):

1. Estimate the STR-ZLB model, compute the residuals $\widetilde{z}_{t}$ and the residual sum of squares $S S R_{0}=\sum_{t=1}^{T} \widetilde{z}_{t}^{2}$.

2. Regress $\widetilde{z}_{t}$ on $\widetilde{h}_{t}^{-1 / 2} \widetilde{\mathbf{s}}_{m t}$ and $\widetilde{\mathbf{z}}_{t-1}$, where the tilde implies that the elements have been estimated under $\mathrm{H}_{0}$, and compute the sum of squared residuals $S S R_{1}$.

3. Compute the test statistic $L M_{\mathrm{ac}}^{T R}=T\left(1-S S R_{1} / S S R_{0}\right)$.

Under $\mathrm{H}_{0}$ and the assumption that the conditional variance is correctly specified, $L M_{\mathrm{ac}}^{T R}$ has an asymptotic $\chi^{2}$ null distribution with $p$ degrees of freedom.

This test results in a strong rejection of the null hypothesis over the entire sample period as well as in subperiods, which agrees with the visual inspection of the residuals. This result is not surprising given the simple dynamic structure of the STR-ZLB model and characteristic of all Taylor rule models based on simple interest rate smoothing. Consequently, care must be exercised in making statistical inferences and, wherever possible, robust standard errors should be employed.

\section{Interpretation}

Figures $3 \mathrm{a}$ and $3 \mathrm{c}$ plot the estimated transition functions on the conditional mean and variance respectively, as a function of the transition variable $i_{t-1}$. The features of the 


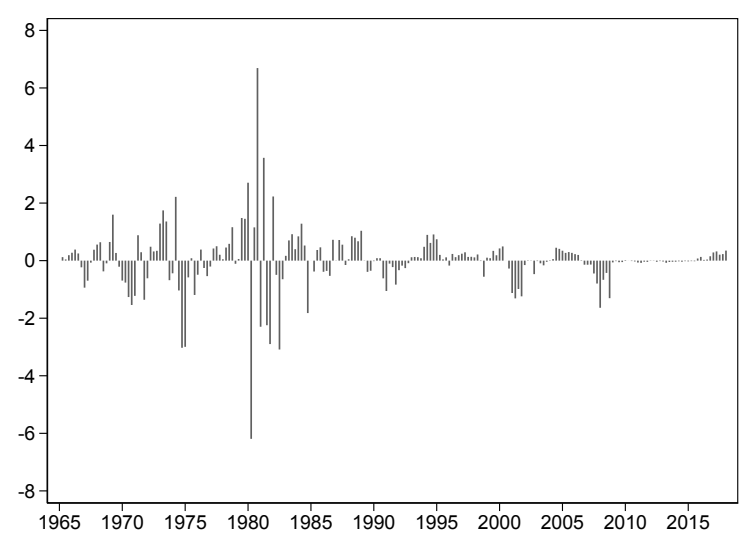

(a) Residuals $\hat{\varepsilon}_{t}$

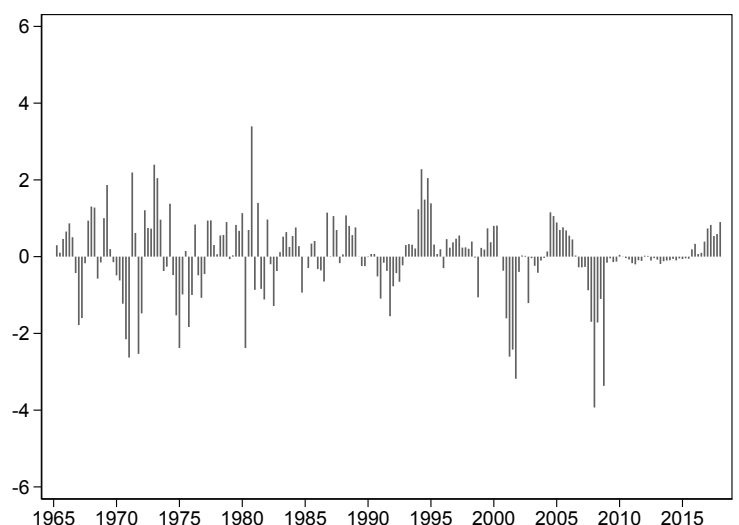

(b) Standardised residuals $\hat{\varepsilon} / \hat{h}_{t}^{1 / 2}$

Figure 2: Residuals and standardised residuals from the estimated STR-ZLB Taylor rule from 1965:Q1 to 2018:Q1.

gamma transition are clear with the zero-lower-bound regime occurring for interest rates near or below zero, and the 'regular' or 'Taylor' regime occurring for interest rates sufficiently above zero. Therefore the model can also be used to accommodate small negative interest rates. An important property of these gamma transition functions is that the model fully arrives at the zero-lower-bound regime $\left(G_{m}=0\right)$ when $i_{t-1} \downarrow 0$.

As may be expected, the estimates for the "Taylor rule component" in (19) are close to the ones in (16), whereas the $\mathrm{AR}(1)$ component closely resembles (18). One of the advantages of the STR-ZLB model is that not only does it parameterise the two extremes, it also describes the (infinitely many) states between these extremes.

The corresponding Figures $3 \mathrm{~b}$ and $3 \mathrm{~d}$ respectively show the estimated mean and variance transitions, plotted over the time span of the dataset. The zero-lower-bound era from 2008 to 2016 is represented by a clear regime shift in the conditional mean. The conditional mean does not completely reach the zero-lower-bound regime, as $G_{m}$ does not fully reach zero, but the mean value of $G_{m}$ during the centre of the zero-lower-bound era (2009:Q1-2014:Q4) is found to be 0.0152. The mean value of the quarterly averaged federal funds rate for the same time period is $i_{t}=0.128 \%$.

On the other hand, from Figure $3 \mathrm{~d}$ it is clear that the transition function in the conditional variance reflects the high degree of variability induced by the monetary policy experiments around 1979-1982. Numerous studies in the United States monetary policy 


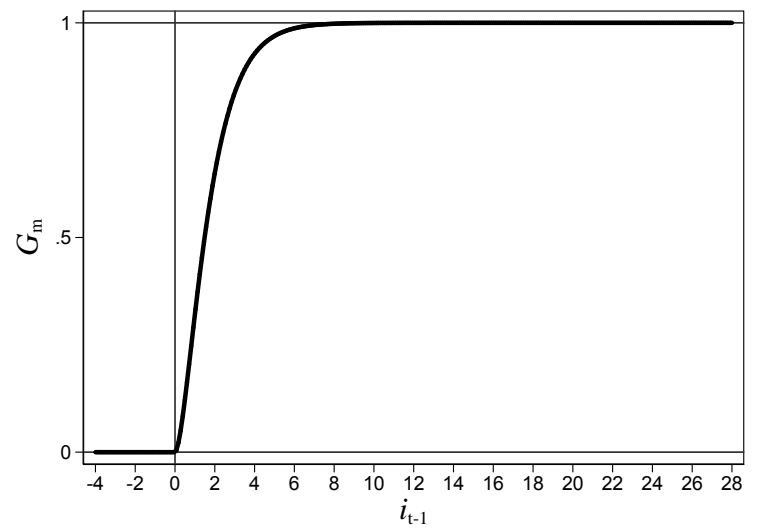

(a) Transition function in the conditional mean as a function of $i_{t-1}$

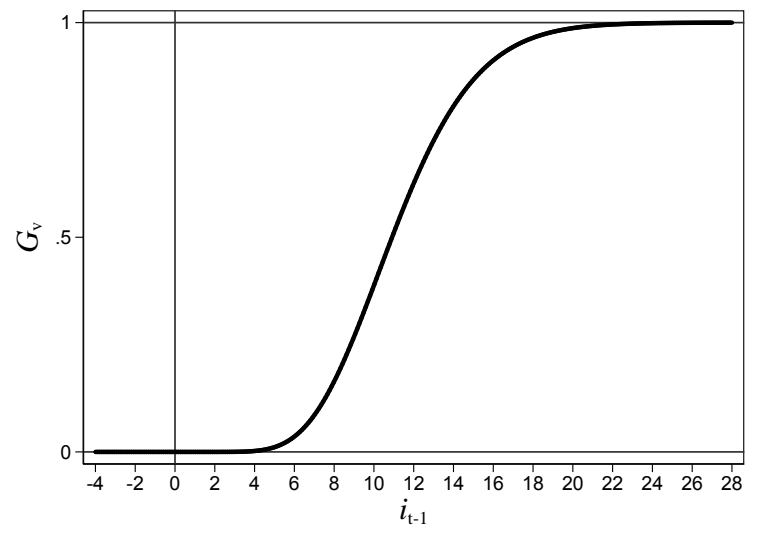

(c) Transition function in the conditional variance as a function of $i_{t-1}$

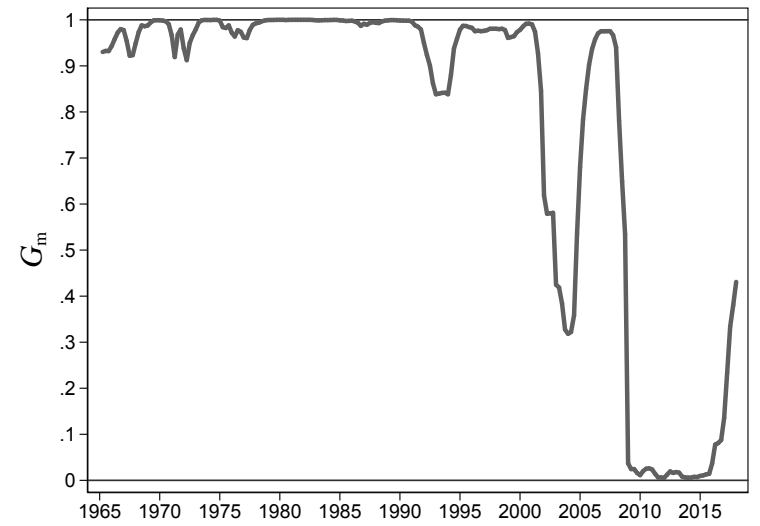

(b) Transition function in the conditional mean as a function of time

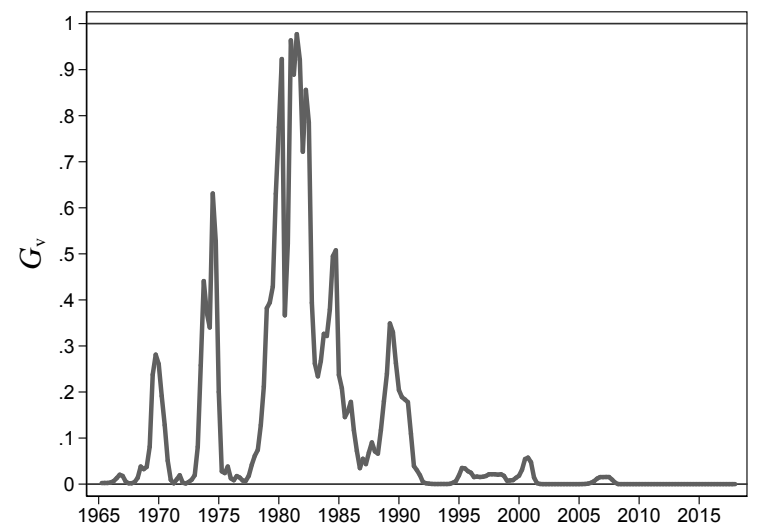

(d) Transition function in the conditional variance as a function of time

Figure 3: Estimation of the STR-ZLB Taylor rule from 1965:Q1 to 2018:Q1. 
literature have found structural breaks in the data during this time period, e.g. Taylor (1999a), Clarida, Galí and Gertler (2000), Orphanides (2004), Yoon (2011), and Yao (2014). In these papers the error variance is assumed constant. In the present work, however, the linear Taylor rule representation is retained for this period, but the timevarying variance accommodates possible inadequacies in the linear rule by allowing the conditional variance to increase during this period. Another interesting feature of the estimation results, visible in Figure 3d, is that the conditional error variance becomes small in the 1990s, long before the beginning of the zero-lower-bound era. This result indicates that the 'regular' dynamic Taylor rule fits the data quite well during this period.

There is an alternative approach to interpreting the estimated conditional mean in equation (19), namely, by viewing it as a linear form Taylor rule with time-varying coefficients given by

$$
i_{t}=\widehat{\beta}_{0}\left(i_{t-1}\right)+\widehat{\beta}_{1}\left(i_{t-1}\right) \pi_{t}+\widehat{\beta}_{2}\left(i_{t-1}\right) y_{t}+\widehat{\beta}_{3}\left(i_{t-1}\right) i_{t-1}+\widehat{\varepsilon}_{t}
$$

The estimated intercept is $\widehat{\beta}_{0}\left(i_{t-1}\right)=\widehat{\alpha}_{0}^{*} \widehat{G}_{m}\left(i_{t-1}\right)+\widehat{\alpha}_{4}=\widehat{\alpha}_{0} \widehat{G}_{m}\left(i_{t-1}\right)+\widehat{\alpha}_{4}\left(1-\widehat{G}_{m}\left(i_{t-1}\right)\right)$, the response to inflation is $\widehat{\beta}_{1}\left(i_{t-1}\right)=\widehat{\alpha}_{1} \widehat{G}_{m}\left(i_{t-1}\right)$, the response to the output gap is $\widehat{\beta}_{2}\left(i_{t-1}\right)=$ $\widehat{\alpha}_{2} \widehat{G}_{m}\left(i_{t-1}\right)$, and the implied interest smoothing coefficient is given by $\widehat{\beta}_{3}\left(i_{t-1}\right)=\widehat{\alpha}_{3}^{*} \widehat{G}_{m}\left(i_{t-1}\right)+$ $\widehat{\alpha}_{5}=\widehat{\alpha}_{3} \widehat{G}_{m}\left(i_{t-1}\right)+\widehat{\alpha}_{5}\left(1-\widehat{G}_{m}\left(i_{t-1}\right)\right)$.

The estimated time-varying coefficients $\widehat{\beta}_{1}\left(i_{t-1}\right), \widehat{\beta}_{2}\left(i_{t-1}\right)$, and $\widehat{\beta}_{3}\left(i_{t-1}\right)$ are plotted against time in Figures 4a to 4c. In Figure 4a, the horizontal line corresponds to the value of $\widehat{\alpha}_{1}$ which is the coefficient on inflation during the linear regime. There is a sharp transition in the value of this coefficient to the lower horizontal line at zero during the zero-lower-bound era. This pattern is repeated in Figure 4b for the output gap parameter $\widehat{\alpha}_{2}$. The coefficient on the lagged interest rate in Figure 4c, however, retains its magnitude over the whole period of observation as the two estimates shown by the horizontal lines $\widehat{\alpha}_{3}$ and $\widehat{\alpha}_{5}$ are not significantly different. It is very interesting to note that after 2015 , the estimated time-varying coefficients on inflation and the output gap both increase as the gamma smooth transition is engaged. This feature demonstrates that the model not only captures the transition into the lower-bound period but it is also effective in modelling the recovery as the economy begins to emerge from the zero-lower-bound era. 


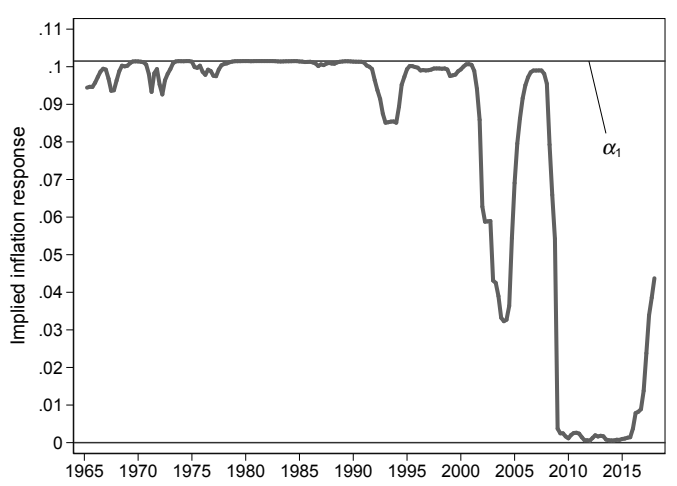

(a) $\widehat{\beta}_{1}\left(i_{t-1}\right)$ over time

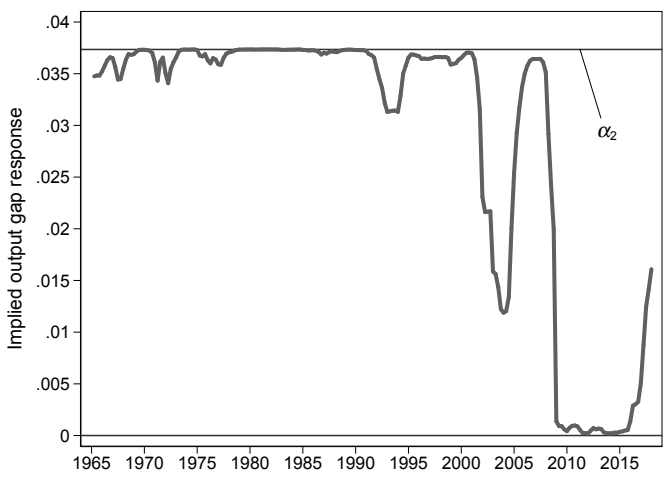

(b) $\widehat{\beta}_{2}\left(i_{t-1}\right)$ over time

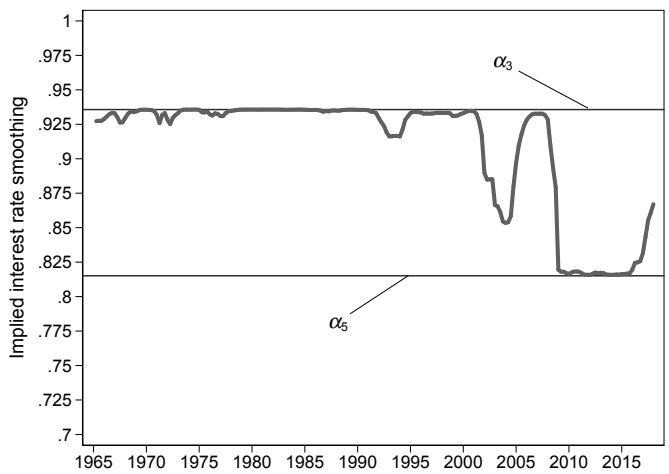

(c) $\widehat{\beta}_{3}\left(i_{t-1}\right)$ over time

Figure 4: Shifts in the estimated time-varying Taylor rule parameters $\beta_{1}\left(i_{t-1}\right)$ (the response to inflation), $\beta_{2}\left(i_{t-1}\right)$ (the response to the output gap), and $\beta_{3}\left(i_{t-1}\right)$ (the interest smoothing coefficient) from the STR-ZLB Taylor rule in the vicinity of the zero lower bound, as shown in equation (21). 


\section{Conclusion}

In contrast to existing nonlinear specifications of the Taylor rule, the STR-ZLB model incorporates smooth transitions in both the conditional mean and conditional variance of the federal funds rate. The specification of the variance is a novel addition to the model and is crucial in ensuring that the short-term interest rate is able to remain at the lower bound. By design, the linear Taylor rule is nested within the STR-ZLB model and completely characterises interest rate behaviour when the lower bound is not binding. In the vicinity of the zero lower bound, the STR-ZLB model resembles an autoregressive process of order one for the interest rate with a vanishing variance. In this way, both conventional and unconventional monetary policy regimes, and the transition between them, are captured by a single model. The model is also applicable outside of the United States because it does not entirely preclude small negative interest rates.

The log-likelihood function of the model is straightforward to derive and maximum likelihood estimates of the model parameters are relatively straightforward to obtain. The estimates of the linear Taylor rule component are very much as expected. The estimates of the transition functions indicate a gradual but clear shift in the conditional mean and conditional variance during the zero-lower bound era. The transitions in the variance also suggest that the linear dynamic Taylor rule does not explain developments of the Volcker period particularly well. The simple dynamic specification of the model retains the essential structure of the Taylor rule but at the cost of serially correlated errors. Care must therefore be exercised to ensure correct inference. 


\section{References}

Aizenman, J., Hutchison, M. and Noy, I.: 2011, Inflation targeting and real exchange rates in emerging markets, World Development 39, 712-724.

Alcidi, C., Flamini, A. and Fracasso, A.: 2011, Policy regime changes, judgment and Taylor rules in the Greenspan era, Economica 78, 89-107.

Amemiya, T.: 1984, Tobit models: a survey, Journal of Econometrics 24, 3-61.

Bauducco, S., Bulír, A. and Čihák, M.: 2008, Taylor rule under financial instability, IMF Working Paper No. 08/18.

Bhar, R. and Malliaris, A. G.: 2016, Asset price momentum and monetary policy: timevarying parameter estimation of taylor rules, Applied Economics 48, 5329-5339.

Boinet, V. and Martin, C.: 2008, Targets, zones, and asymmetries: a flexible nonlinear model of recent UK monetary policy, Oxford Economic Papers 60, 423-439.

Boivin, J.: 2006, Has U.S. monetary policy changed? Evidence from drifting coefficients and real-time data, Journal of Money, Credit and Banking 38, 1149-1173.

Caporale, G. M., Helmi, M. H., Çatık, A. N., Ali, F. M. and Akdeniz, C.: 2018, Monetary policy rules in emerging countries: is there an augmented nonlinear Taylor rule?, Economic Modelling 72, 306-319.

Casellina, S. and Uberti, M.: 2008, Optimal monetary policy and long-term interest rate dynamics: Taylor rule extensions, Computational Economics 32, 183-198.

Clarida, R., Galí, J. and Gertler, M.: 1998, Monetary policy rules in practice: some international evidence, European Economic Review 42, 1033-1067.

Clarida, R., Galí, J. and Gertler, M.: 2000, Monetary policy rules and macroeconomic stability: evidence and some theory, The Quarterly Journal of Economics 115, 147180.

Creel, J. and Hubert, P.: 2015, Has inflation targeting changed the conduct of monetary policy?, Macroeconomic Dynamics 19, 1-21. 
Engle, R. F.: 1982, Autoregressive conditional heteroscedasticity with estimates of the variance of United Kingdom inflation, Econometrica 50, 987-1006.

Fuhrer, J. C.: 1997, Inflation/output variance trade-offs and optimal monetary policy, Journal of Money, Credit and Banking 29, 214-234.

Fuhrer, J. C. and Tootell, G. M. B.: 2008, Eyes on the prize: how did the Fed respond to the stock market?, Journal of Monetary Economics 55, 796-805.

Godfrey, L. G.: 1978, Testing against general autoregressive and moving average error models when the regressors include lagged dependent variables, Econometrica 46, 1293-1301.

Gonzales, L. A. A. and Vera, A. P.: 2002, Monetary policy, Taylor's rule and instability, Metroeconomica 53, 1-24.

Goodfriend, M.: 1991, Interest rates and the conduct of monetary policy, CarnegieRochester Conference Series on Public Policy 34, 7-30.

Hamilton, J. D.: 2017, Why you should never use the Hodrick-Prescott filter, NBER Working Paper No. 23429.

Huang, Y.-F.: 2015, Time variation in U.S. monetary policy and credit spreads, Journal of Macroeconomics 43, 205-215.

Jung, T., Teranishi, Y. and Watanabe, T.: 2005, Optimal monetary policy at the zerointerest-rate bound, Journal of Money, Credit and Banking 37, 813-835.

Kasaï, N. and Naraidoo, R.: 2012, Financial assets, linear and nonlinear policy rules: an in-sample assessment of the reaction function of the South African Reserve Bank, Journal of Economic Studies 29, 161-177.

Kato, R. and Nishiyama, S. I.: 2005, Optimal monetary policy when interest rates are bounded at zero, Journal of Economic Dynamics and Control 29, 97-133.

Kim, D. H., Osborn, D. R. and Sensier, M.: 2005, Nonlinearity in the Fed's monetary policy rule, Journal of Applied Econometrics 20, 621-639. 
Koustas, Z. and Lamarche, J.-F.: 2012, Estimation of a nonlinear Taylor rule using realtime U.S. data, Studies in Nonlinear Dynamics $\&$ Econometrics 16, 1-16.

Krugman, P. R.: 1991, Target zones and exchange rate dynamics, Quarterly Journal of Economics 106, 669-682.

Lanne, M. and Saikkonen, P.: 2005, Nonlinear GARCH models for highly persistent volatility, Econometrics Journal 8, 251-276.

Lee, D. J. and Son, J. C.: 2013, Nonlinearity and structural breaks in monetary policy rules with stock prices, Economic Modelling 31, 1-11.

Lundbergh, S. and Teräsvirta, T.: 2006, A time series model for an exchange rate in a target zone with applications, Journal of Econometrics 131, 579-609.

Martin, C. and Milas, C.: 2010, Testing the opportunistic approach to monetary policy, The Manchester School 78, 110-125.

Martin, C. and Milas, C.: 2013, Financial crises and monetary policy: evidence from the UK, Journal of Financial Stability 9, 654-661.

Nikolsko-Rzhevskyy, A. and Papell, D. H.: 2013, Taylor's rule versus Taylor rules, International Finance 16, 71-93.

Nikolsko-Rzhevskyy, A., Papell, D. H. and Prodan, R.: 2014, Deviations from rules-based policy and their effects, Journal of Economic Dynamics and Control 49, 4-17.

Okun, A. M.: 1962, Potential GNP: its measurement and significance, Proceedings of the Business and Economic Statistics Section of the American Statistical Association, pp. $98-104$.

Orphanides, A.: 2004, Monetary policy rules, macroeconomic stability, and inflation: a view from the trenches, Journal of Money, Credit and Banking 36, 151-175.

Petersen, K.: 2007, Does the Federal Reserve follow a non-linear Taylor rule?, University of Connecticut Economics Working Papers 200737.

Reifschneider, D. and Williams, J. C.: 2000, Three lessons for monetary policy in a lowinflation era, Journal of Money, Credit and Banking 32, 936-966. 
Roskelley, K. D.: 2016, Augmenting the Taylor rule: monetary policy and the bond market, Economics Letters 144, 64-67.

Rudebusch, G. D.: 2002, Term structure evidence on interest rate smoothing and monetary policy inertia, Journal of Monetary Economics 49, 1161-1187.

Rudebusch, G. D.: 2006, Monetary policy inertia: fact or fiction?, International Journal of Central Banking 2, 85-135.

Ruge-Murcia, F. J.: 2006, The expectations hypothesis of the term structure when interest rates are close to zero, Journal of Monetary Economics 53, 1409-1424.

Taylor, J. B.: 1993, Discretion versus policy rules in practice, Carnegie-Rochester Conference Series on Public Policy 39, 195-214.

Taylor, J. B.: 1999a, A historical analysis of monetary policy rules, Monetary Policy Rules, University of Chicago Press, Chicago, pp. 319-347.

Taylor, J. B.: 1999b, The robustness and efficiency of monetary policy rules as guidelines for interest rate setting by the European central bank, Journal of Monetary Economics 43, 655-679.

Taylor, J. B.: 2001, The role of the exchange rate in monetary-policy rules, The American Economic Review 91, 263-267.

Taylor, J. B. and Williams, J. C.: 2011, Simple and robust rules for monetary policy, in B. M. Friedman and M. Woodford (eds), Handbook of Monetary Economics, Vol. 3, Elsevier B.V., chapter 15, pp. 829-859.

Wooldridge, J. M.: 1990, A unified approach to robust, regression-based specification tests, Econometric Theory 6, 17-43.

Wu, J. C. and Xia, F. D.: 2016, Measuring the macroeconomic impact of monetary policy at the zero lower bound, Journal of Money, Credit and Banking 48, 253-291.

Yao, F.: 2014, Stabilising Taylor rules when the supply shock has a unit root, Journal of Macroeconomics 41, 16-20. 
Yoon, G.: 2011, Structural breaks and smooth transition autoregressive processes: an application to the US stock value ratios, Applied Economics 43, 2313-2320.

Zhu, Y. and Chen, H.: 2017, The asymmetry of U.S. monetary policy: evidence from a threshold Taylor rule with time-varying threshold values, Physica A 473, 522-535. 
2018-13: Emilio Zanetti Chini: Forecasting dynamically asymmetric fluctuations of the U.S. business cycle

2018-14: Cristina Amado, Annastiina Silvennoinen and Timo Teräsvirta: Models with Multiplicative Decomposition of Conditional Variances and Correlations

2018-15: Changli He, Jian Kang, Timo Teräsvirta and Shuhua Zhang: The Shifting Seasonal Mean Autoregressive Model and Seasonality in the Central England Monthly Temperature Series, 1772-2016

2018-16: $\quad$ Ulrich Hounyo and Rasmus T. Varneskov: Inference for Local Distributions at High Sampling Frequencies: A Bootstrap Approach

2018-17: $\quad$ Søren Johansen and Morten Ørregaard Nielsen: Nonstationary cointegration in the fractionally cointegrated VAR model

2018-18: Giorgio Mirone: Cross-sectional noise reduction and more efficient estimation of Integrated Variance

2018-19: Kim Christensen, Martin Thyrsgaard and Bezirgen Veliyev: The realized empirical distribution function of stochastic variance with application to goodness-of-fit testing

2018-20: Ruijun Bu, Kaddour Hadri and Dennis Kristensen: Diffusion Copulas: Identification and Estimation

2018-21: Kim Christensen, Roel Oomen and Roberto Renò: The drift burst hypothesis

2018-22: $\quad$ Russell Davidson and Niels S. Grønborg: Time-varying parameters: New test tailored to applications in finance and macroeconomics

2018-23: Emilio Zanetti Chini: Forecasters' utility and forecast coherence

2018-24: Tom Engsted and Thomas Q. Pedersen: Disappearing money illusion

2018-25: $\quad$ Erik Christian Montes Schütte: In Search of a Job: Forecasting Employment Growth in the US using Google Trends

2018-26: Maxime Morariu-Patrichi and Mikko Pakkanen: State-dependent Hawkes processes and their application to limit order book modelling

2018-27: $\quad$ Tue Gørgens and Allan H. Würtz: Threshold regression with endogeneity for short panels

2018-28: $\quad$ Mark Podolskij, Bezirgen Veliyev and Nakahiro Yoshida: Edgeworth expansion for Euler approximation of continuous diffusion processes

2018-29: Isabel Casas, Jiti Gao and Shangyu Xie: Modelling Time-Varying Income Elasticities of Health Care Expenditure for the OECD

2018-30: Yukai Yang and Luc Bauwens: State-Space Models on the Stiefel Manifold with A New Approach to Nonlinear Filtering

2018-31: Stan Hurn, Nicholas Johnson, Annastiina Silvennoinen and Timo Teräsvirta: Transition from the Taylor rule to the zero lower bound 